\title{
Fatigue Behavior of Ti-Ni-Cu Thin Wires SME
}

\author{
C.J. de Araújo( $\left.{ }^{1}\right)$, M. Morin and G. Guénin \\ C.E.M.P.P.M., URA 341 du CNRS, INSA de Lyon, 20 avenue Albert Einstein, 69621 Villeurbanne cedex, \\ France
}

\begin{abstract}
Practical applications of the Shape Memory Effect (SME) involves frequently repetitive operations. Therefore, it's essential to have knowledge of the properties behavior related to SME under working conditions. The thermomechanical fatigue of $\mathrm{Ti}-\mathrm{Ni}-\mathrm{Cu}$ thin wires loaded by static uniaxial tensile stress and submitted to thermal cycling has been studied. The test samples were cycled until failure in oil bath, cooled by this one and heated by electrical current. One modified Wöhler curve has been plotted and the influences of the applied stress and of the number of thermal cycles on the shape memory properties has been analyzed. It is shown that the martensitic transformation associated to SME changes according to stress level and/or number of thermal cycles. The degradation until failure of the Stress Assisted Two-way Memory Effect (SATWME) was set between 0 and $20 \%$ compared to initial value.
\end{abstract}

\section{INTRODUCTION}

The fatigue life of a structural material is directly relationed to cyclic performances. In the case of the Shape Memory Alloys (SMA) different types of fatigue can be considered [1-3]. One of these types is the degradation of the reversible shape memory effect due to thermal cycles under constant stress, here called Stress Assisted Two-Way Memory Effect (SATWME). Today, degradation and fatigue are considered important drawbacks on the design and use of SMA-actuators which can be inserted as parts of smart structures $[4,5]$.

The thermal cycling between $M_{f}$ and $A_{f}$ temperatures under constant stress cause the martensitic transformation with preferential orientation of the martensite variants. During repeated transformation cycles, the shape memory characteristics associated to martensitic transformation should be severely changed especially when no training procedure has been realized. There are many studies describing the changes of the thermomechanical properties of SMA during thermal cycling under constant stress used as training procedure [6-10]. However, these treatments are performed during few number of thermal cycles compared to fatigue life.

This paper describes the thermomechanical behavior of $\mathrm{Ti}-\mathrm{Ni}-\mathrm{Cu}$ thin wires SME during high thermal cycling until failure. The effects of the applied stress and of the number of thermal cycles on the shape memory properties are discussed. One modified Wöhler curve reveal the fatigue life of the studied wires.

\section{EXPERIMENTAL}

The commercial wires $(\phi=0.5 \mathrm{~mm})$ used in this study has a nominal chemical composition Ti-45.0Ni$5.0 \mathrm{Cu}$ (\%at). As received materials, with $35 \%$ of cold-work, were heat treated at $425^{\circ} \mathrm{C}$ for $1 \mathrm{~h}$ followed by cooling in air and slightly polished for to remove oxide layers. The transformation temperatures under stress-free conditions, measured by DSC (Mettler TA 3000) and according to French Norm [11], were: $M_{f}(90 \%)=27.3^{\circ} \mathrm{C}, M_{s}(10 \%)=35.7^{\circ} \mathrm{C}, A_{s}(90 \%)=42.7^{\circ} \mathrm{C}$ and $A_{f}(10 \%)=53.3^{\circ} \mathrm{C}$.

Two views of the SME fatigue apparatus is shown in figure 1(a). This apparatus allow to test two samples simultaneously. Thermal cycles are performed by forced convection in silicone oil (slow cycles) or by electrical heating and cooling by circulation of silicone oil at constant temperature below $\mathrm{M}_{\mathrm{f}}$ (fast cycles).

Figures 1(b) and 1(c) show the thermal cyclic loading mode and the strain vs temperature typical curve obtained during a slow cycle with some characteristic points. Each slow cycle is performed when

( ${ }^{1}$ ) On leave of absence from Universidade Federal da Paraiba, DEM/CCT, Campina Grande-PB, Brazil 
the $2^{n}$ cycles are attained, where $\mathrm{n}$ is an integer number. The period of one cycle was $3.6 \mathrm{ks}$ and $6 \mathrm{~s}$ for slow cycles and fast cycles, respectively.

Specimens having a gauge length between 28 and $30 \mathrm{~mm}$ were loaded in martensitic state and heated above $A_{f}$ and the temperature cycling then began. Constant applied stresses was set between 100 and $450 \mathrm{MPa}$ for tests until failure. The strains are calculated from the length 1 of the specimen by $\varepsilon=\left(1-l_{0}\right) / l_{0}$ with $l_{0}$ the initial length of the specimen at room temperature, i.e., in martensitic state.

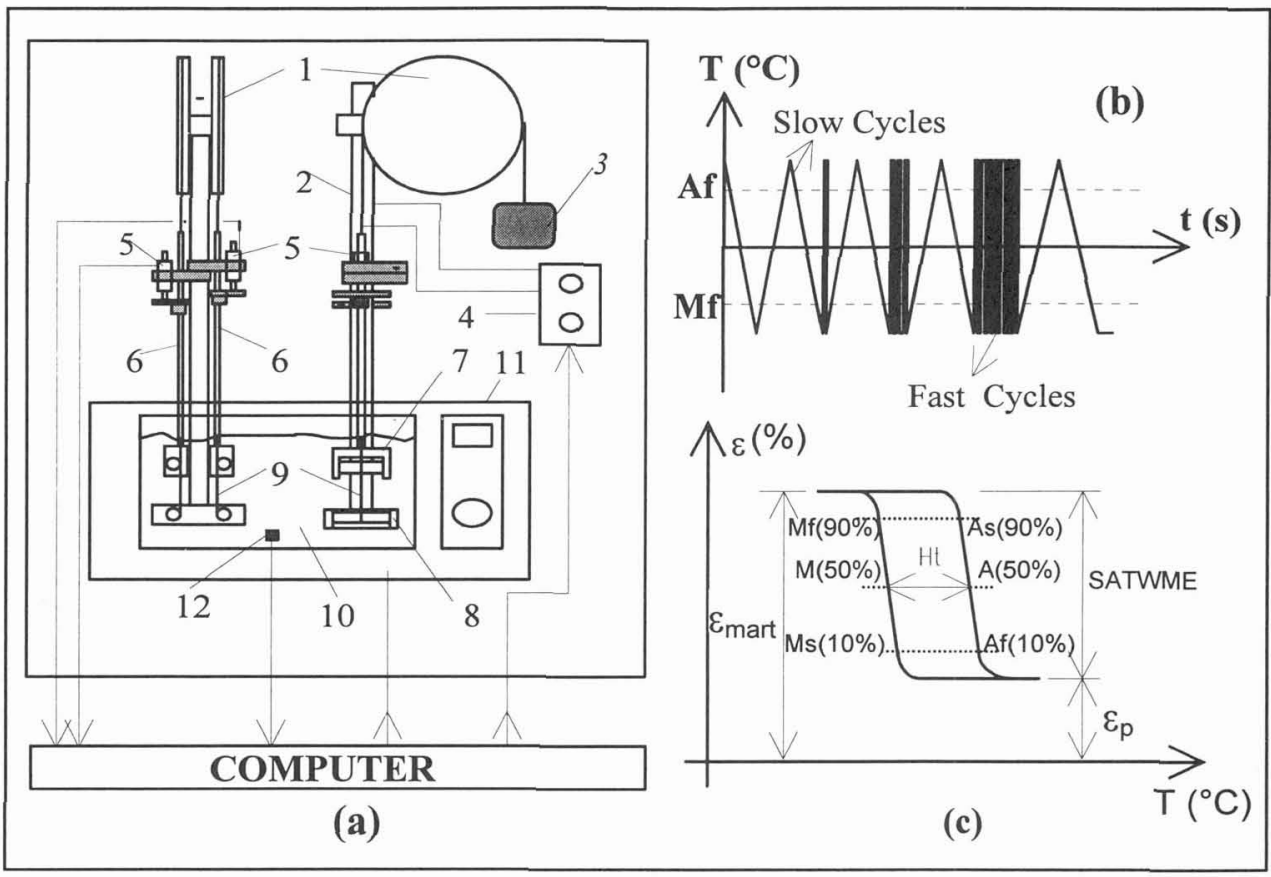

Figure 1. (a) Schematic overview of the fatigue test apparatus. 1: pulleys; 2: fixed INVAR rod; 3: weight; 4: electrical current source; 5: displacement transducers; 6: mobile INVAR rods; 7: mobile grip; 8: fixed grip; 9: samples; 10: silicone oil; 11: thermal regulation apparatus (heating, cooling and stirring elements); 12: PT 100 resistance thermometer. (b) Thermal cyclic loading mode. (c) Typical curve obtained for slow cycles.

\section{RESULTS}

\subsection{Transformation Dependence on the Stress Level}

Thermomechanical tests were carried out on different samples, each one loaded by different stress levels and thermally cycled until failure. The shape memory characteristics are defined in figure 1(c). The effect of the applied stress on the shape memory properties associated to transformation was analyzed at the first complete thermal cycle. The figure 2 shows the influence of the applied stress on the different strains and on the characteristic temperatures. In figure 2(a) the strain curves show that in a initial stage (stage 1), between 100 and $275 \mathrm{MPa}, \varepsilon_{\text {mart }}$ and SATWME increases and $\varepsilon_{\mathrm{P}}$ has a limited value. However, in a second stage (stage 2), for stresses greater than $275 \mathrm{MPa}, \varepsilon_{\text {mart }}$ and SATWME are practically constant and $\varepsilon_{\mathrm{P}}$ is also constant but, with much larger values than those of the initial stage. Figure 2 (b) shows that the transformation temperatures has linear relationships with the applied stress. The slope $d \sigma / d T$, for the first stage, is 8.2 and $7.9 \mathrm{MPa} /{ }^{\circ} \mathrm{C}$ for $\mathrm{M}_{\mathrm{s}}(10 \%)$ and $\mathrm{A}_{\mathrm{s}}(90 \%)$, as well. The temperatures plotted for zero stress were determined by DSC. For all cases, two stages was observed for a critical stress of about 275 $\mathrm{MPa}$, likewise to strain-stress behavior. For the second stage $\mathrm{A}_{\mathrm{s}}<\mathrm{M}_{\mathrm{s}}$ and $\mathrm{Ht}$ is lowered compared to initial stage. 

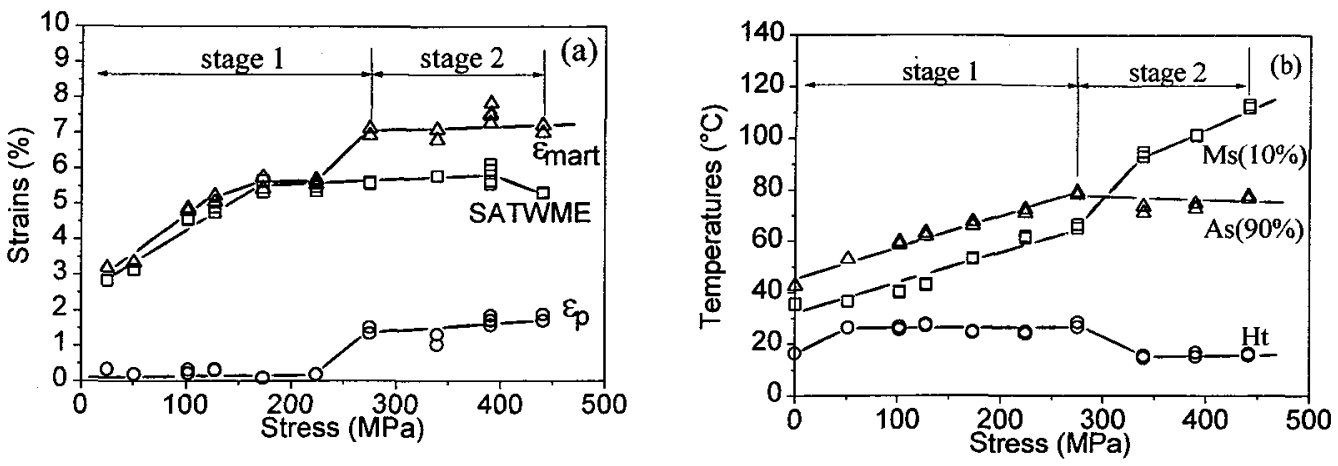

Figure 2 - Stress dependence of shape memory properties measured at the first thermal cycle (a) $\varepsilon_{\text {mart }}$, SATWME and $\varepsilon_{\mathrm{p}}$. (b) Transformation temperatures and hysteresis.

\subsection{Transformation Dependence on the Thermal Cycling Under Constant Loading}

Figure 3 shows the changes of $\varepsilon$-T curves as a function of the number of thermal cycles $(\mathrm{N})$ for $127 \mathrm{MPa}$, $275 \mathrm{MPa}$ and $441 \mathrm{MPa}$. For $127 \mathrm{MPa}$ can be seen clearly in figure 3(a) that about $80 \%$ of the martensitic transformation occurs suddenly at Ms. For $275 \mathrm{MPa}$, drastic changes in the shape of the $\varepsilon$-T curves take place during cycling as shown in figure 3(b). In this case, during the 16 first cycles, the transformation is similar to that of $\sigma<275 \mathrm{MPa}$. Afterward, the cycles becomes such as those for $\sigma>275 \mathrm{MPa}$ shown in figure 3(c), where can be seen that the transformation occurs in a large temperature domain.
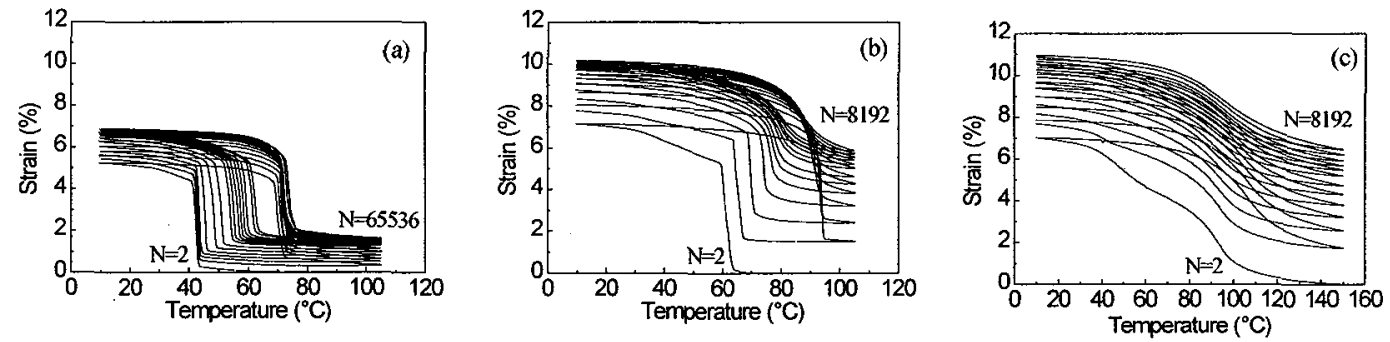

Figure 3 - Strain-temperature curves under constant stresses for (a) $127 \mathrm{MPa}$, (b) $275 \mathrm{MPa}$ and (c) $441 \mathrm{MPa}$.

The transformation strains ( $\varepsilon_{\text {mart }}$ and SATWME) and plastic strain $\left(\varepsilon_{\mathrm{p}}\right)$ measured in figure 3 are plotted as a function of the number of thermal cycles in figure 4(a). The evolution of the $\varepsilon_{\text {mart }}$ and $\varepsilon_{\mathrm{p}}$ is normally proportional to applied stress. The dependence of the transformation temperatures on stress and number of thermal cycles obtained in figure 3 is shown in figures $4(\mathrm{~b})$. These figures show that the changes in $\mathrm{M}_{\mathrm{s}}(10 \%)$ and $\mathrm{H}_{\mathrm{t}}$ accompanying the thermal cycling are more large for $275 \mathrm{MPa}$.

\subsection{Degradation and Fatigue Life}

Figure 5(a) shows the degradation of the SATWME during repeated transformation cycles as function of the applied stresses. For a stress range between 100 and $173 \mathrm{MPa}$, the SATWME increases or is almost constant until failure. For all other stress levels, greater than $173 \mathrm{MPa}$, loss of SATWME is observed but, its maximum value is limited at about $20 \%$. This degradation phenomenon is not necessarily proportional to external applied stress. 
The number of cycles to failure $\left(\mathrm{N}_{\mathrm{f}}\right)$ has been plotted against the external applied stress and shown in figure 5(b). A linear relationship may be assumed to exist between $\ln N_{f}$ and the applied stress. The $\sigma$ $N_{f}$ relation can be expressed by the empirical equation showed in figure 5(b).
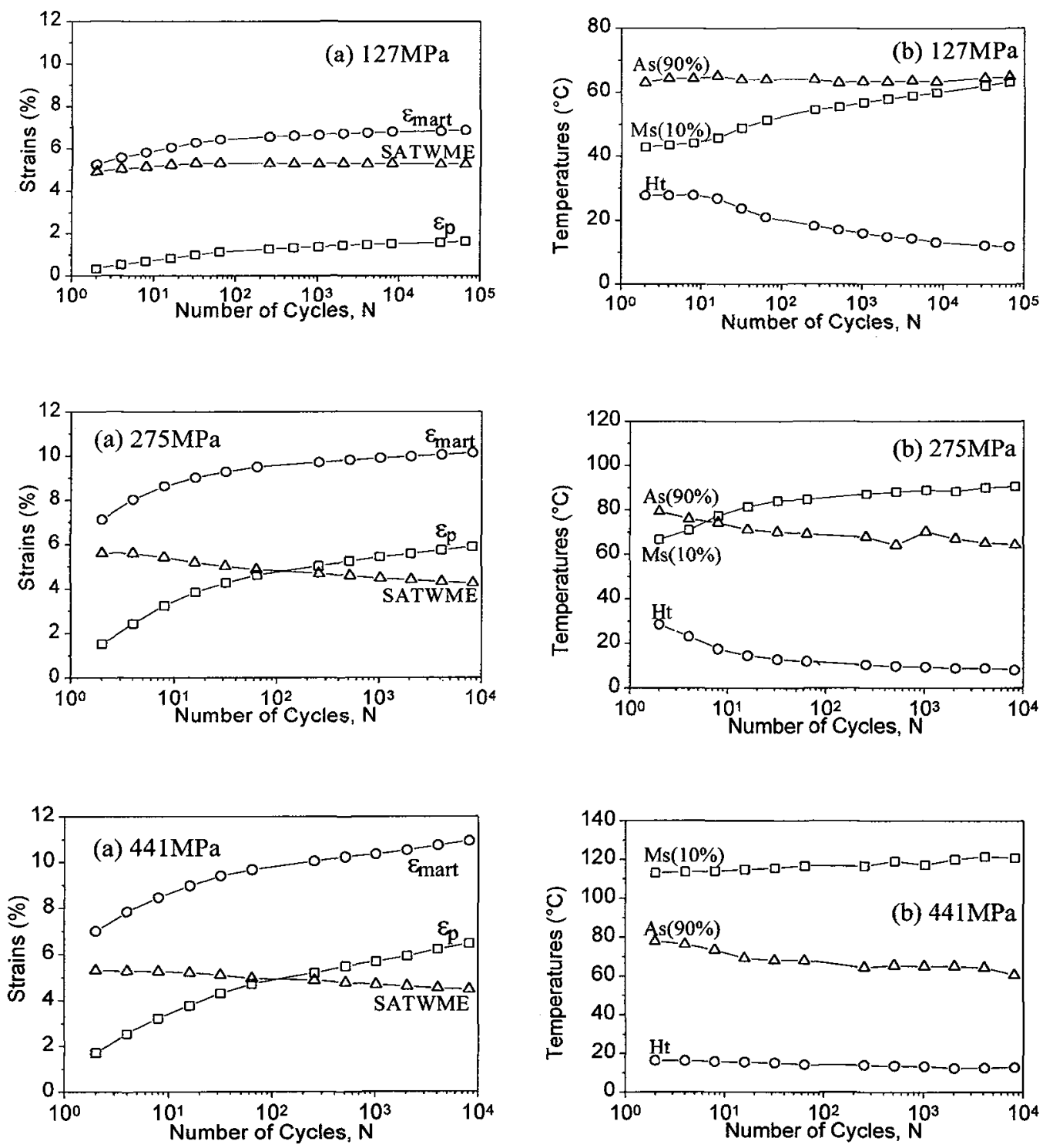

Figure 4 - Shape memory properties during cycles for 127, 275 and $441 \mathrm{MPa}$. (a) strains, (b) temperatures and hysteresis. 

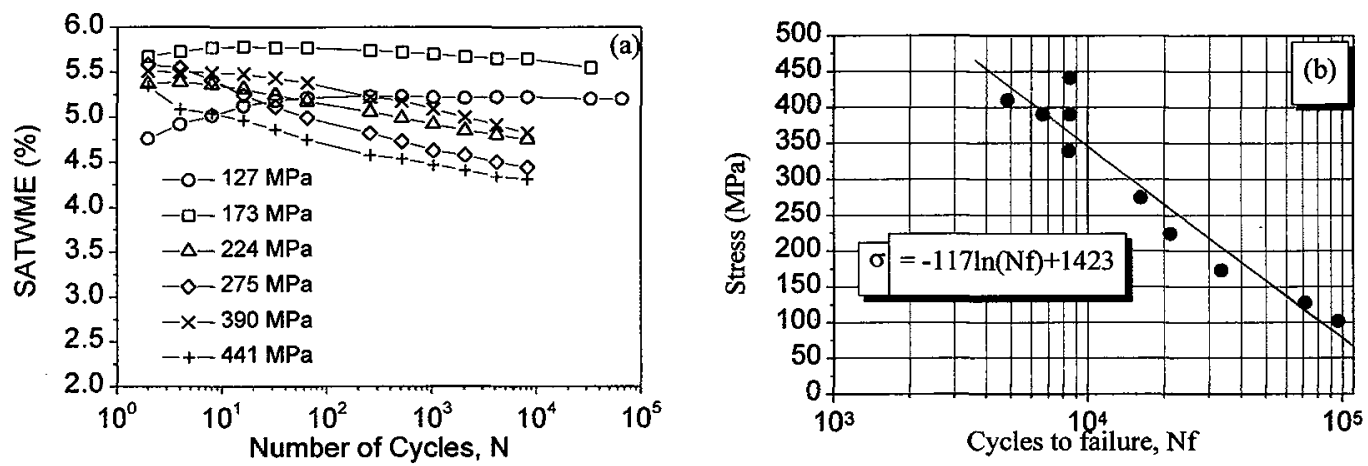

Figure 5 - (a) SATWME vs N. (b) Lifetime of the wires vs external applied stress.

\section{DISCUSSION}

The recoverable strain in a shape memory polycristal depends on the texture, the transformation strain of the martensitic transformation and on the change of symmetry during transformation [12]. However, under constant loading the recoverable strain is also limited by a critical applied stress level which can induce macroscopic slip strain leading to lattice defects and loss of recoverability. For the studied wires this critical stress for inducing martensite variants with the most favorable orientation, corresponding to a maximum $\varepsilon_{\text {mart }}$ at the first thermal cycle, was about $275 \mathrm{MPa}$. The maximum recoverable strain under loading (SATWME) and low plastic strain were obtained for a stress level close to this critical stress.

The origin of the deviation from the linearity related to stages 1 and 2 showed in figure 2(b) is not clear. Nam et al [13] found similar results for a Ti-Ni-Cu alloy with 5 at\% $\mathrm{Cu}$. They considered that the change of the slope is closely related to the plastic strain introduced during the transformation under load.

The thermal cycling under stress free conditions can lead to irreversible processes into SMA which changes its transformation characteristics. For example, Miyazaki et al [14] showed that in Ti-Ni alloys the $\mathrm{M}_{\mathrm{S}}$ temperature is raised or lowered depending on the initial state of specimens. On the other hand, Ti-Ni-Cu alloys are less sensitive to transformation cycling if compared to others SMA [15]. In our case, the heat-treated Ti-Ni-Cu wire was cycled ( 20 cycles) into DSC apparatus and not any changes in thermal properties was observed. From the above mentioned, it is concluded that the behavior of the transformation temperatures shown in figure 4(b) may be attributed to the stress applied during cycling. This behavior is opposite to the one that has been found in some cases for $\mathrm{Cu}-\mathrm{Zn}-\mathrm{Al}$ alloys [6].

It is clear in figure 3 and 4 that, for conditions of thermal cycling under constant loading, the modified martensite start temperature $\left(\mathrm{M}_{s}^{\sigma}\right)$ increases, the true plastic strain accumulates and the hysteresis temperatures $(\mathrm{Ht})$ progressively decreases over many cycles for all studied stress levels as also reported in other works $[3,6,8,10,16,17]$. However, a drastic change in strain-temperature curves during the first cycles as shown in figure $3(\mathrm{~b})$ is rarely mentioned. These behaviors are linked to mechanisms of generation, orientation and movement of defects, especially dislocations which are created in parent phase introducing a strong history dependence in the strain-temperature characteristics [18, 19]. But, it appears that these developed substructures are a function of the applied stress because, for low stresses $(\sigma<175 \mathrm{MPa}$ ), there is not loss of recoverability (SATWME). Then, in these cases the transformation is probably supported by a internal stress field associated with these dislocations substructures. 
If we consider that all thermomechanical properties are stabilized after $10 \%$ of the fatigue life as verified in figure 4 and 5(a), we can say that the development of degradation effects in the studied Ti-Ni-Cu shape memory wires is a phenomenon possible of control, especially for low stresses $(\sigma<175$ $\mathrm{MPa}$, in our case). But, in all cases, the failure occur suddenly without strong anomalies in shape memory properties.

The figure 5(b) shows that no fatigue limit exists within the extent of stress in the present work. But, fatigue limit may be possible, perhaps, for lower stress levels $(<100 \mathrm{MPa})$ and/or incomplete transformations.

\section{CONCLUSIONS}

The cyclic performance in thermal cycling mode under constant tensile stress of $\mathrm{Ti}-\mathrm{Ni}$-Cu wires has been studied. We have found that degradation of the shape memory properties is strongly dependent on the applied stress for the range of 100-450 MPa. For low stress ( $<175 \mathrm{MPa}$ ) the plastic strain evolution is limited (1-1.6\%) and the SATWME is raised or constant until failure. For greater stresses $(>175 \mathrm{MPa})$, the plastic strain range is larger (4-6\%), the SATWME is lowered by $20 \%$ at maximum and the changes in temperature properties are less pronounced compared to the low stress range. On the other hand, for all stress levels, the shape memory properties are stabilized after about $10 \%$ of the fatigue life and the loss of recoverability is weak if compared to others SMA. The lifetime of the as prepared wires may be estimated by one empirical equation of the modified Wöhler curve.

\section{Acknowledgment}

C. J. De Araujo would like to thank the CAPES Brazilian Agency for its financial support in France.

\section{References}

1. Van Humbeeck, J., Journal de Physique IV (1991), pp. C4-189 - C4-197.

2. Hornbogen, E., in Engineering Aspects of Shape Memory Alloys, Eds. T. W. Duerig et al, pp.267-279, Butterworth-Heinemann, London, 1990.

3. Tang, W. and Sandström, R., Materials \& Design 14 (1993), No.2, pp.103-113.

4. Van Humbeeck, J., Proc. ICIM 96, Lyon-France, Ed. by P. F. Gobin and J. Taltibouët, 442-451, 1996.

5. Van Humbeeck, J., Materials Technology 11 (1996), No.2, pp.55-61.

6. Stalmans, R., Van Humbeeck, J. and Delaey, L., Acta Metall. 40 (1992), No.3, pp.501-511.

7. Todoroki, T., Tamura, H. and Suzuki, Y., Proc. ICOMAT 86, pp.748-753.

8. Contardo, L., Doctoral Thesis, INSA of Lyon, 1988.

9. Contardo, L. and Guénin, G., Proc. ICOMAT 89, Materials Science Forum 56-58 (1990), pp.529-534.

10. Rodriguez, P. and Guénin, G., Proc. ICOMAT 89, Materials Science Forum 56-58 (1990), pp.541546.

11. French Norm NF A 51-080, Shape Memory Alloys (SMA)-Vocabulary and Measures, 1991.

12. Bhattacharya, K. and Kohn, R. V., Acta Metall. 44 (1996), No.2, pp.529-542.

13. Nam, T.H., Saburi, T. and Shimizu, K., Materials Transactions, JIM 31 (1990), No.11, pp.959-967.

14. Miyazaki, S., Igo, Y. and Otsuka, K., Acta Metall. 34 (1986), No.10, pp.2045-2051.

15. Moberly, W. J. and Melton, K. N., in Engineering Aspects of Shape Memory Alloys, Eds. T. W. Duerig et al, pp.46-57, Butterworth-Heinemann, London, 1990.

16. Stachowiak, G. B. and McCormick, P. G., Acta Metall. 36 (1988), No.2, pp.291-297.

17. Bigeon, M.J. and Morin, M., Proc. ESOMAT 94, Journal de Physique IV, Colloque C2, Supplément au Journal de Physique III, Vol.5, C2-385 - C2-390, 1995.

18. Filip, P. and Mazanec, K., Scripta Metall. 30 (1994), pp.67-72.

19. Jesse Lim, T. and McDowell, L., Journal of Intelligent Material Systems and Structures 6 (1995), pp.817-830. 